\title{
Double anticholinergic therapy for refractory neurogenic and non- neurogenic detrusor overactivity in children: Long-term results of a prospective open-label study
}

\author{
Geneviève Nadeau, MD; ${ }^{*}$ Annette Schröder, MD; ${ }^{\dagger}$ Katherine Moore, MD; ${ }^{*}$ Lucie Genois, RN; ${ }^{*}$ \\ Pascale Lamontagne, RN; ${ }^{*}$ Micheline Hamel, RN; ${ }^{*}$ Ève Pellerin; ${ }^{*}$ Stéphane Bolduc, MD, FRCSC*
}

*Division of Urology, Centre Hospitalier Universitaire de Québec (CHUQ), Université Laval, Québec, QC ; 'Department of Urology, Hospital for Sick Children, Toronto, ON

See related article on page 181.

Cite as: Can Urol Assoc J 2014;8(5-6):175-80. http://dx.doi.org/10.5489/cuaj.1362

Published online June 16, 2014.

\section{Abstract}

Introduction: In this study, we optimize pharmacotherapy in children who failed anticholinergic monotherapy by simultaneous administration of 2 anticholinergics (oxybutynin and/or tolterodine and/or solifenacin).

Methods: This report is an update of our previously published study on double anticholinergic regimen in children with refractory incontinence due to neurogenic (NDO) and non-neurogenic (DO) detrusor overactivity. Patients with an insufficient response (clinically/urodynamically) to an optimized dose of a single anticholinergic (oxybutynin or tolterodine) received a second anticholinergic (tolterodine or solifenacin), in addition to the pre-existing medication. The primary end-point was efficacy (continence) and the secondary end-points were tolerability and safety. The Patient Perception of Bladder Condition (PPBC) scale was used to rate subjective improvement of patients.

Results: In total, 56 patients with DO $(n=31)$ or NDO $(n=25)$ were enrolled at a mean age of $11.4 \pm 3.5$ years and were followed for a minimum of 3 months. The duration of double treatment was $36 \pm 23$ months. Our results found that 23 patients became dry, 18 improved significantly and 15 improved moderately. Urodynamic capacity improved from $158 \pm 87 \mathrm{~mL}$ to $359 \pm 148 \mathrm{~mL}$ and maximal pressure of contractions decreased from $76 \pm 24$ to $22 \pm 22 \mathrm{cmH}_{2} \mathrm{O}(p<0.0001)$. The overall success rate was $82 \%$, since 10 patients discontinued treatment for unsatisfactory clinical response or bothersome side effects. No side effects were reported by 28 patients, mild side effects by 20 , moderate side effects by $8 ; 2$ patients withdrew from the study due to their side effects. Of the 35 patients who voided spontaneously, 8 developed post-void residuals ( $>20 \%$ ).

Conclusions: With a larger cohort and prospective follow-up, we reiterated that double anticholinergic regimen in children with DO or NDO refractory to anticholinergic monotherapy is a feasible and efficient approach.

\section{Introduction}

Incontinence due to overactive bladder syndrome with neurogenic (NDO) or non-neurogenic (DO) detrusor overactivity negatively affects the daily life of many children. Seven anticholinergic agents are commercially available, and 5 have been studied in children. Currently, only oxybutynin has FDA approval for use in children.

Initial treatment includes behavioural modification and approved oral medications at recommended dosing. For patients with intractable symptoms, before considering more invasive strategies, the first step is usually an increased dose of the single anticholinergic, which naturally increases the likelihood of bothersome side effects. Possible subsequent steps include intravesical instillation of oxybutynin, ${ }^{1,2}$ sacral neuromodulation, ${ }^{3-5}$ or intradetrusor injection of botulinum toxin. ${ }^{6-9}$ Most of these methods are still under evaluation in the pediatric population. ${ }^{10}$ For patients with NDO, failure of non-surgical treatments may finally lead to invasive surgery, such as augmentation enterocystoplasty to preserve renal function.

Combining 2 different anticholinergics appears as a conservative and reversible option, even though side effects may potentially be additive. Therefore, we wanted to explore this approach, especially in a pediatric population in which postponing more aggressive measures is desirable.

To do this, we prospectively studied a cohort of pediatric patients with persistent incontinence and incomplete urodynamic response to a single and long-acting anticholinergic at the highest well-tolerated dose ("optimized dose"). Our purpose was to optimize the medical therapy by combining 2 different anticholinergic agents. Our preliminary report 
Nadeau et al.

was on 33 patients. ${ }^{11}$ We now present the long-term use and extension of our open-label study. More patients were recruited and data from previously enrolled patients were updated as of September 2012. We assessed efficacy, tolerability, safety, and patients/parents satisfaction.

\section{Methods}

Children with DO or NDO, persistent incontinence and only partial urodynamic response to an optimized dose of a single extended-release anticholinergic medication were offered to enter a prospective open-label protocol. This study was approved by our institutional ethic board committee and informed consent was obtained. Enrolment criteria were: (1) medical and behavioural therapies had failed to cure urgency and incontinence; (2) absence of correctable neurological anomalies evaluated by magnetic resonance imaging for NDO patients; and (3) incomplete clinical and urodynamic responses despite use of an optimized dose (without side effects) of one long-acting anticholinergic medicine.

Before inclusion in the study, patients completed a questionnaire, physical exam, urodynamic study (UDS), abdominal ultrasound and voiding cystourethrogram (VCUG). All patients underwent thorough behavioural modification protocol. A single long-acting anticholinergic medication (oxybutynin extended release [ER] or tolterodine ER) was then initiated at the lowest weight-adjusted dose. The dose was increased until the resolution of symptoms, occurrence of intolerable side effects, or until the maximum dose was reached (30 mg for oxybutynin ER, $4 \mathrm{mg}$ for tolterodine ER). If the minimal daily dose of $10 \mathrm{mg}$ of long-acting oxybutynin was not well-tolerated, it was exchanged for long-acting tolterodine (Fig. 1).

UDS were obtained for each patient after a minimum of 6 months on monotherapy. Persistent involuntary detrusor contractions were confirmed in all patients before adding the second anticholinergic. The first anticholinergic was continued at the highest well-tolerated dose. The second anticholinergic was usually tolterodine ER $4 \mathrm{mg}$, but if the response was suboptimal or the medication not well-tolerated, solifenacin 5 to $10 \mathrm{mg}$ was offered (Fig. 1). This was based on a previous report by our group demonstrating the efficacy and safety of an adjusted-dose regimen of solifenacin to treat children who are refractory to oxybutynin or tolterodine. ${ }^{12}$ Subsequent changes in dosage or medication were then done according to symptom improvement.

During the systematic 3-month follow-up, the questionnaire, physical exam, 3-day voiding diary, post-void residual (PVR) and urinalysis/cultures were repeated. Every 6 months, abdominal ultrasound and UDS were repeated for all patients; VCUG was obtained annually for NDO patients and DO patients with a history of urinary tract infection (UTI). Blood samples and electrocardiogram (EKG) were also

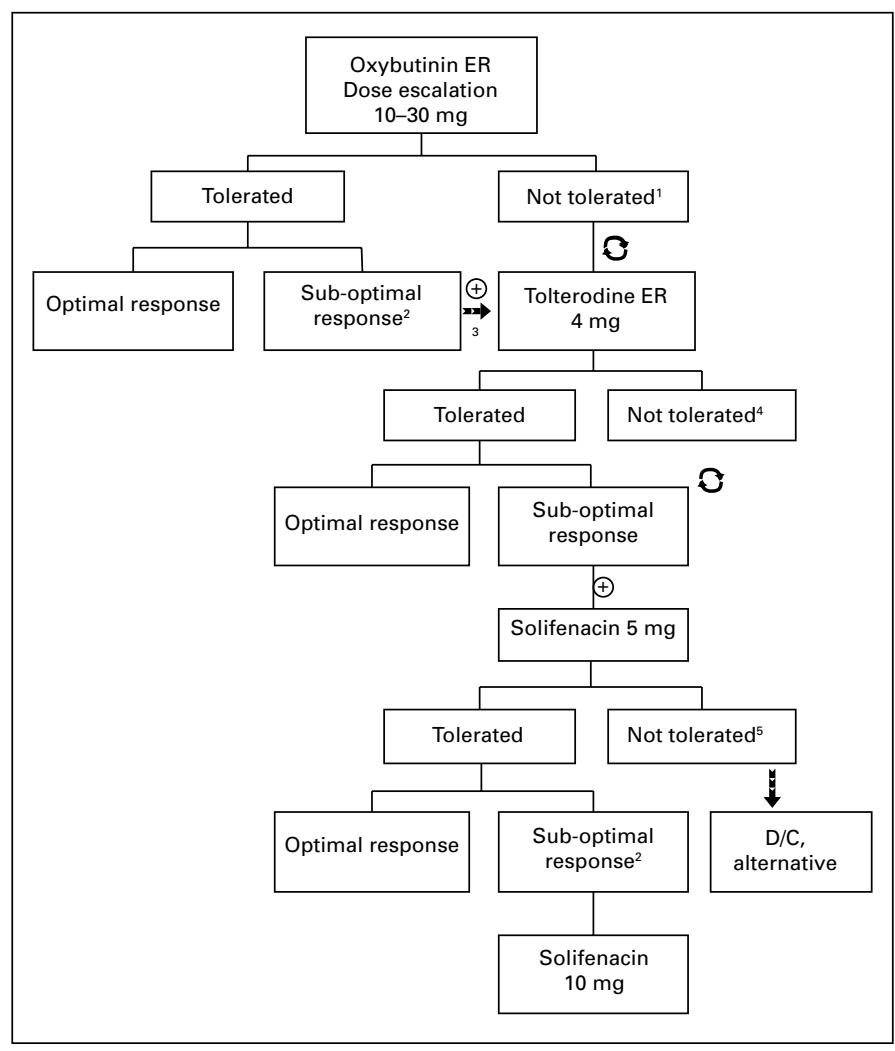

Fig. 1. Algorithm for decision making for introduction of a second anticholinergic. 'If oxybutinin ER was not well tolerated, it was discontinued and changed for Tolterodine ER $4 \mathrm{mg}$. ${ }^{2}$ Suboptimal response: based on clinical and/or urodynamic study criteria. ${ }^{3}$ Introduction of the second anticholinergic medication. ${ }^{4} \mathrm{ff}$ tolterodine ER $4 \mathrm{mg}$ was not well tolerated as a second anticholinergic medication, it was discontinued and changed for solifenacin 5 $\mathrm{mg}$. If solifenacin was not well-tolerated, it was discontinued and alternative treatment was offered. $\odot$ Addition of medication; $\boldsymbol{Q}:$ change of medication.

obtained at entry and every 6 months to detect potential toxicity.

Results and determination of success were documented based on subjective relief of symptoms, objective voiding diaries and UDS parameters, the latter 2 following the International Children's Continence Society (ICCS) classification. ${ }^{13}$ Parents or patients supervised by their parents rated symptom relief efficacy on a questionnaire as complete cure (defined as dryness), improvement (a reduction by at least $90 \%$ in incontinence episodes) or partial improvement (a reduction by 50\%-

\begin{tabular}{ll}
\hline Table 1. The 6-Item Patient Perception of Bladder Condition \\
(PPBC) scale bladder condition: Subject assessment \\
\hline My bladder condition: \\
\hline 1 & does not cause me any problems at all \\
2 & causes me some very minor problems \\
3 & causes me some minor problems \\
4 & causes me (some) moderate problems \\
5 & causes me severe problems \\
6 & causes me many severe problems \\
\hline
\end{tabular}


Double anticholinergic medication in children

\begin{tabular}{|c|c|c|c|c|c|c|}
\hline \multirow[t]{2}{*}{$\begin{array}{c}\text { Type of bladder } \\
\text { dysfunction }\end{array}$} & \multicolumn{2}{|c|}{ Gender } & \multirow[t]{2}{*}{$\begin{array}{l}\text { Age at initiation of second } \\
\text { anticholinergic (years), mean (SD) }\end{array}$} & \multicolumn{2}{|c|}{ Voiding pattern } & \multirow[t]{2}{*}{$\begin{array}{c}\text { Treatment duration } \\
\text { (months), mean (SD) }\end{array}$} \\
\hline & $\mathrm{M}$ & $\mathrm{F}$ & & Spontaneous & $\mathrm{CIC}$ & \\
\hline Neurogenic & 14 & 11 & $12.8(3.7)$ & 5 & 20 & $47.0(19.2)^{*}$ \\
\hline Non-neurogenic & 21 & 10 & $10.2(3.0)$ & 30 & 1 & $26.9(22.3)^{*}$ \\
\hline All & 35 & 21 & $11.4(3.5)$ & 35 & 21 & $35.9(23.1)$ \\
\hline
\end{tabular}

M: male; F: female; SD: standard deviation; CIC: clean intermittent catheterization; *Treatment duration was different for neurogenic vs. non-neurogenic patients ( $p=0.001)$.

89\%). Improvement in bladder capacity and decrease in the number and intensity of detrusor contractions were correlated with improvement of incontinence symptoms. Effectiveness was also assessed using the Patient Perception of Bladder Condition (PPBC) scale on a 6-point scale ranging from 1 to 6 (Table 1$),{ }^{14}$ at study initiation and every 6 months.

Tolerability was assessed by documenting side effects, by means of a questionnaire administered by a urology nurse. Side effects were graded as none, mild (does not interfere with the patient's usual function), moderate (interferes to some extent) and severe (interferes significantly). Compliance was evaluated by questionnaire and assessment of the medication containers, and 3 categories were used: (1) medication taken $>90 \%$ of the time; (2) $50 \%$ to $89 \%$ of the time and (3) less than $50 \%$ of the time.

Clinical variables were compared across groups using the Pearson chi-square test for categorical data. Continuous data were analyzed by Student $t$ or Mann-Whitney $U$ tests. Normality of distribution was assessed using the ShapiroWilk $W$-test. Patients were censored when data were lacking. The Wilcoxon signed-rank or paired $t$ tests were used for comparisons of treatment effects within each group. A $p$ value of less than 0.05 was considered statistically significant, and all tests were two-sided. All statistical analyses were performed using SPSS Statistics 21.0 Software (SPSS 21.0, SPSS Inc., Chicago IL).

\section{Results}

The study included 56 patients (21 girls, 35 boys). In total, 25 children with NDO and 31 with DO were followed for a minimum of 3 months after the initiation of the second anticholinergic on the combined treatment (Table 2). The mean age at initiation of the second anticholinergic agent was $11.4 \pm 3.5$ years (range: $6-18$ ). Different combinations and doses of medication were used (Table 3). The mean treatment duration with the double therapy was 36 months (range: 3-89).

Assessment of symptom relief showed that continence improved in all patients. Supervised by their parents, patients rated an improvement of $100 \%$ (complete dryness) in 23 cases $(41 \%)(10 \mathrm{NDO} / 13 \mathrm{DO}),>90 \%$ reduction of incontinence episodes in 18 (32\%) (7 NDO/11 DO) and a 50-89\% reduction in $15(27 \%)$ ( $7 \mathrm{NDO} / 8 \mathrm{DO})$. The mean PPBC score at baseline was $5.0( \pm 0.6)$ and decreased significantly to 1.8 $( \pm 0.7 ; p<0.0001)$ at the end-point (Table 4, Fig. 2$)$.

Mean voided volumes, cystometric bladder capacity and maximum pressure of detrusor contractions all improved significantly with treatment (Table 5). The number of incontinence episodes per day was significantly decreased from initiation of combination therapy to end of study $(p<0.0001)$ (Table 4).

All EKG and blood tests remained normal, except for mild isolated lactate dehydrogenase elevation in 3 patients, who received a combination of oxybutynin and solifenacin. Imaging showed no deterioration of the upper urinary tract. Twenty-eight (50\%) patients did not report any side effects. A subgroup of $20(36 \%)$ patients described mild side effects (17 xerostomia, 1 constipation, 1 blurred vision, 1 headache) and $8(14 \%)$ experienced moderate side effects ( 7 xerostomia, 1 aggressive behaviour). Side effects were equally reported by the neurogenic $(n=13)$ and non-neurogenic $(\mathrm{n}=15)$ patients $(p=0.8)$. The compliance to medication was excellent $(>90 \%)$ and only 2 patients with NDO discontinued treatment due to their side effects (xerostomia, high PVR).

\begin{tabular}{|c|c|c|c|c|}
\hline Medication (mg) & Tolterodine ER 4 & Solifenacin 5 & Solifenacin 10 & Total no. patients (NDO, DO) \\
\hline Oxybutynin ER 10 & 0 & 0 & 3 & $3(0,3)$ \\
\hline Oxybutynin ER 15 & 2 & 1 & 11 & $14(4,10)$ \\
\hline Oxybutynin ER 20 & 4 & 0 & 19 & $23(14,9)$ \\
\hline Oxybutynin ER 30 & 0 & 0 & 7 & $7(3,4)$ \\
\hline Tolterodine ER 4 & - & 1 & 8 & $9(4,5)$ \\
\hline $\begin{array}{l}\text { Total no. patients (NDO, } \\
\text { DO) }\end{array}$ & $6(5,1)$ & $2(0,2)$ & $48(20,28)$ & $56(25,31)$ \\
\hline
\end{tabular}


Of the 35 patients who voided spontaneously, 8 developed significant PVR ( $>20 \mathrm{~mL}$, as per the ICCS) (5 DO; 3 NDO). Six patients improved following the initiation of biofeedback, 1 child with DO was started on clean intermittent catheterization and 1 with NDO discontinued combination therapy. Four symptomatic urinary tract infections (UTI) were documented in patients who voided spontaneously, including 3 patients with de novo high PVR. Two patients developed multiple cavities, possibly secondary to xerostomia. There was no relationship between the intensity of the side effects, dose and type of medication used.

At the end of follow-up, $36(64 \%)$ patients were still on both medications. Twenty patients had stopped combination treatment: 10 because they became dry (and remained dry up until last follow-up) and 10 because of side effects or unsatisfactory clinical improvement. These last 10 patients, all with NDO, were offered other treatment modalities (botulinum toxin or augmentation enterocystoplasty) (Table 6). The overall success rate was $82 \%(46 / 56)$, and more specifically $100 \%$ for DO and $60 \%$ (15/25) for NDO, which was significantly different $(p=0.0498)$.

\section{Discussion}

In the present study, we found that the addition of a second, different anticholinergic is a successful approach in most children with refractory DO and NDO for improving the continence status, surprisingly without the anticipated increase in side effects in most patients. The final urodynamic and clinical parameters all improved (Table 5, Table 6), correlating overall with efficacy of treatment. The overall success rate was higher among the non-neurogenic patients. This could potentially be explained by the fact that neurogenic bladders are often more refractory to medical therapies, as previously pointed out by several groups..$^{15-17}$

Combining 2 drugs with the same mode of action is not unique (e.g., triple therapy in HIV treatment), ${ }^{18}$ but this is also clearly not a widespread concept. The main concern is that not only the therapeutic benefits may be synergistic or additive, but side effects may as well. Antimuscarinics are the mainstay of treatment of overactive bladder, but they have also been studied in combination with biofeedback, alpha-blockers, tricyclic antidepressants and DDAVP. ${ }^{15,19}$

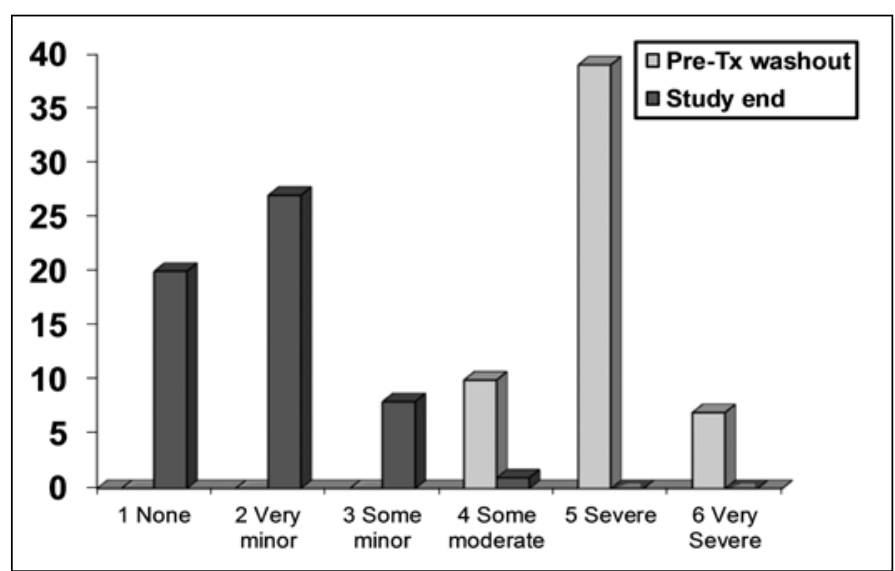

Fig. 2. Patient Perception of Bladder Condition (PPBC) scores at pre-study washout and at study end. Lower scores indicate improvement.

Recently published guidelines by the American Urological Association on the management of DO in adults state that there is a paucity of literature addressing combination therapy of antimuscarinics with each other or with other classes of medication, such as tricyclics to recommend its use. ${ }^{20}$

Despite the above concerns, 2 groups have reported on antimuscarinics combination for the treatment of overactive bladder in adults. Amend and colleagues found that a double antimuscarinic regimen was effective, with a success rate of $85 \%$, among 27 patients with NDO, ${ }^{21}$ while $\mathrm{Yi}$ and colleagues reported a success rate of $67 \%$ for 49 patients with idiopathic DO treated with a combination of 2 antimuscarinics for a mean duration of 9 months.

Overall, our long-term results compare advantageously with these studies and support safety and tolerability of combination therapy. No major adverse event was reported, and only 2 patients required a change of regimen due to bothersome side effects. We observed an incidence of $23 \%$ of high PVRs in the voiding population. This emphasizes the importance of regular tests and treatment of PVR in all patients, who need to be informed about this possible consequence of the treatment before initiation of the second anticholinergic.

It is worth noting that most patients who discontinued one or both drugs did so because they became dry or because of suboptimal control of their symptoms, rather than for unbearable side effects. Indeed, 5 patients (DO) stopped

\begin{tabular}{|c|c|c|c|c|}
\hline \multirow[t]{2}{*}{ Type of bladder dysfunction } & \multicolumn{2}{|c|}{ Incontinence ${ }^{1}$ events / day, mean (SD) } & \multicolumn{2}{|c|}{ PPBC score ${ }^{2}$ mean (SD) } \\
\hline & Before & After & Before & After \\
\hline Neurogenic & $3.7(0.9)$ & $0.5(0.8)$ & $4.9(0.5)$ & $2.0(0.8)$ \\
\hline Non-neurogenic & $3.4(0.6)$ & $0.3(0.3)$ & $5.0(0.6)$ & $1.7(0.6)$ \\
\hline All & $3.6(0.7)$ & $0.4(0.6)$ & $5.0(0.6)$ & $1.8(0.7)$ \\
\hline
\end{tabular}

SD: standard deviation. Before: Mean number of incontinence episodes per day on 3-day voiding diary when initiating study. After: Mean number of incontinence episodes per day on 3-day voiding diary at last follow-up. PPBC: Patient perception of Bladder Condition (scale 1 to 6 ). ${ }^{1}$ The number of incontinence episodes per day was significantly decreased during anticholinergic combination therapy; overall, neurogenic and non-neurogenic patients $(p<0.0001)$. ${ }^{2}$ PBC scores significantly decreased from start to end of study; overall, neurogenic and non-neurogenic groups $(p<0.0001)$. 


\begin{tabular}{|c|c|c|c|c|c|c|}
\hline \multirow[t]{2}{*}{$\begin{array}{l}\text { Type of bladder } \\
\text { dysfunction }\end{array}$} & \multicolumn{2}{|c|}{$\begin{array}{c}\text { Voided }^{\dagger} \text { volume }(\mathrm{mL})^{1} \text { voiding diary, } \\
\text { mean (SD) }\end{array}$} & \multicolumn{2}{|c|}{$\begin{array}{l}\text { Urodynamic capacity }(\mathrm{mL})^{1} \text {, mean } \\
\text { (SD) }\end{array}$} & \multicolumn{2}{|c|}{$\begin{array}{l}\text { Amplitude of detrusor contractions } \\
\text { (cmH } \\
\text { ( } \mathrm{O}) \text {, mean (SD) }\end{array}$} \\
\hline & Before & After & Before & After & Before & After \\
\hline Neurogenic & $184(92)^{2}$ & $369(144)^{2}$ & $209(103)^{3}$ & $419(172)^{3}$ & $64(26)$ & $22(18)$ \\
\hline Non-neurogenic & $95(27)^{2}$ & $294(102)^{2}$ & $117(38)^{3}$ & $309(104)^{3}$ & $85(17)$ & $22(25)$ \\
\hline All & $135(78)$ & $327(127)$ & $158(87)$ & 359 (148) & $76(24)$ & $22(22)$ \\
\hline
\end{tabular}

SD: standard deviation; 'Voided or catheterized volumes; 'Bladder capacity evaluated by 3-day voiding diary and UDS was significantly improved during combination treatment; overall,

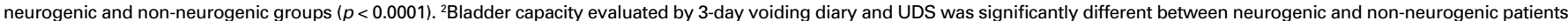

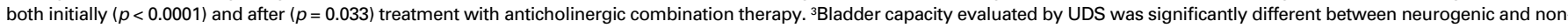

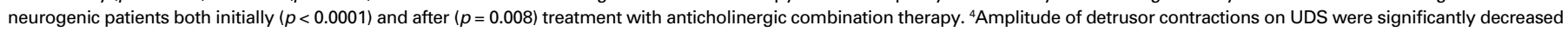
by combination treatment; overall, neurogenic and non-neurogenic groups $(p<0.0001)$.

\begin{tabular}{|c|c|c|c|c|c|c|c|c|}
\hline \multirow[t]{2}{*}{ Type of bladder dysfunction } & \multicolumn{3}{|c|}{ Still on combination, dosage } & \multicolumn{4}{|c|}{ Stopped 1 or both medications } & \multirow[t]{2}{*}{ Total } \\
\hline & Stable & $\uparrow$ & $\downarrow$ & Dry & S/E & Botox & Augment & \\
\hline Neurogenic & 12 & 1 & 1 & 1 & 2 & 7 & 1 & 25 \\
\hline Non-neurogenic & 20 & 2 & 0 & 9 & 0 & 0 & 0 & 31 \\
\hline All & 32 & 3 & 1 & 10 & 2 & 7 & 1 & 56 \\
\hline
\end{tabular}

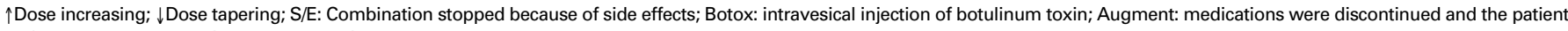
underwent an augmentation enterocystoplasty.

both medications sequentially and another 5 (1 NDO, 4 DO) remained dry after stopping 1 of the 2 agents up until the last follow-up. Only 2 patients with NDO stopped the treatment because of xerostomia or a high PVR. The intensity of the side effects experienced in children is often less bothersome than in adults, even when the dose per kilogram is higher. As hypothesized in our previous report, differences in antimuscarinic metabolites and their target receptors among drugs could explain why there did not seem to be an addition or multiplication of side effects on the combination regimen. ${ }^{11}$

The prevailing theory to explain the enhanced efficacy of combination of anticholinergics over monotherapy could be the result of differences in antimuscarinic metabolites that would act on different target receptors. Amend and colleagues also hypothesized that patients refractory to highdosage monotherapy might be fast metabolizers who would benefit from higher doses. ${ }^{21}$ Finally, as suggested by other groups, ${ }^{21,22}$ there could be a synergistic or additive effect of both drugs on the receptors. Considering that the pathophysiology of overactive bladder is not fully understood, there is clearly a need for more research to shed light on the exact mechanism of action.

We acknowledge the limitations and bias inherent to the nonrandomized uncontrolled design of our study, especially since a high placebo response is well known in adults and meaningful differences with the active drug are sometimes difficult to demonstrate. ${ }^{23}$ However, we believe the magnitude of the observed changes in urodynamic parameters could hardly be explained by the placebo effect only. Obviously, a dose titration regimen is required to properly evaluate the balance between clinical benefits and side effects on an individual basis. A better understanding of the pharmacokinetics and dynamics, as well as a vigilance of such a strategy, remains of paramount importance.

\section{Conclusion}

A double anticholinergic regimen is a safe and efficient approach in the escalation of treatment in children with DO or NDO refractory to anticholinergic monotherapy even in long-term use. High subjective and objective success rates were achieved for both groups, suggesting the feasibility of this conservative strategy for all patients with drug-refractory incontinence, regardless of their primary pathology. This therapeutic alternative could be included in the management algorithm for intractable overactive bladder symptoms, although we acknowledge the need for a prospective randomized controlled study before official acceptance.

Competing interests: Dr. Nadeau, Dr. Schröder, Dr. Moore, Dr. Genois, Dr. Lamontagne, Dr. Hamel, Dr. Pellerin and Dr. Bolduc all declare no competing financial or personal interests.

This paper has been peer-reviewed.

\section{References}

1. Kaplinsky R, Greenfield S, Wan J, et al. Expanded followup of intravesical oxybutynin chloride use in children with neurogenic bladder. J Urol 1996;156:753-6. http://dx.doi.org/10.1016/S0022$5347(01) 65806-3$

2. Aubert D, Cencig P, Royer M. Treatment with oxybutynin hydrochloride of urinary incontinence and hyperactive bladder conditions in children [in French]. Ann Pediatr (Paris) 1986;33:629-34. 
Nadeau et al.

3. Roth TJ, Vandersteen DR, Hollatz $P$, et al. Sacral neuromodulation for the dysfunctional elimination syndrome: A single center experience with 20 children. J Urol 2008;180:306-11. http://dx.doi. org/10.1016/i.juro.2008.03.033

4. Humphreys MR, Vandersteen DR, Slezak JM, et al. Preliminary results of sacral neuromodulation in 23 children. J Urol 2006;176:2227-31. http://dx.doi.org/10.1016/i.juro.2006.07.013

5. Groen $L A$, Hoebeke $P$, Loret $N$, et al. Sacral neuromodulation with an implantable pulse generator in children with lower urinary tract symptoms: 15-year experience. J Urol 2012;188:1313-8. http://dx.doi. org/10.1016/i.juro.2012.06.039

6. Schurch B, Corcos J. Botulinum toxin injections for paediatric incontinence. Curr Opin Urol 2005; 15:264-7. http://dx.doi.org/10.1097/01.mou.0000172401.92761.86

7. McDowell DT, Noone D, Tareen F, et al. Urinary incontinence in children: Botulinum toxin is a safe and effective treatment option. Pediatr Surg Int 2012;28:315-20. http://dx.doi.org/10.1007/s00383011-3039-5

8. Schulte-Baukloh H, Michael T, Schobert J, et al. Efficacy of botulinum-a toxin in children with detrusor hyperreflexia due to myelomeningocele: Preliminary results. Urology 2002;59:325-7. http://dx.doi. org/10.1016/50090-4295(01)01641-7

9. Romero RM, Rivas S, Parente A, et al. Injection of botulinum toxin (BTX-A) in children with bladder dysfunction due to detrusor overactivity [in Spanish]. Actas Urol Esp 2011;35:89-92. http://dx.doi. org/10.1016/i.acuro.2010.08.005

10. Tekgul SNR, Hoebeke P, Canning D, et al. Diagnosis and management of urinary incontinence in childhood. In: Incontinence-4th International Consultation. Paris: Health Publications; 2009.

11. Bolduc $S$, Moore K, Lebel $S$, et al. Double anticholinergic therapy for refractory overactive bladder. J Urol 2009;82:2033-9. http://dx.doi.org/10.1016/i.juro.2009.05.099

12. Bolduc $S$, Moore $K$, Nadeau $G$, et al. Prospective open label study of solifenacin for overactive bladder in children. J Urol 2010;184:1668-73. http://dx.doi.org/10.1016/i.juro.2010.03.124

13. Neveus $T$, von Gontard A, Hoebeke, $P$, et al. The standardization of terminology of lower urinary tract function in children and adolescents: report from the Standardisation Committee of the International Children's Continence Society. J Urol 2006; 176: 314-24. http://dx.doi.org/10.1016/S0022-5347(06)00305-3

14. Coyne KS, Matza LS, Kopp Z, et al. The validation of the patient perception of bladder condition (PPBC): A single-item global measure for patients with overactive bladder. Eur Urol 2006;49:1079-86. http:// dx.doi.org/10.1016/i.eururo.2006.01.007
15. Cameron AP, Clemens JQ, Latini IM, et al. Combination drug therapy improves compliance of the neurogenic bladder. J Urol 2009;182:1062-7. http://dx.doi.org/10.1016/i.juro.2009.05.038

16. Horstmann M, Schaefer T, Aguilar Y, et al. Neurogenic bladder treatment by doubling the recommended antimuscarinic dosage. Neurourol Urodyn 2006;25:441-5. http://dx.doi.org/10.1002/nau.20289

17. Razdan $S$, Leboeuf $L$, Meinbach DS, et al. Current practice patterns in the urologic surveillance and management of patients with spinal cord injury. Urology 2003;61:893-6. http://dx.doi.org/10.1016/ S0090-4295(02)02518-9

18. Wertheimer Al, Morrison A. Combination Drugs: Innovation. Pharmacotherapy Pharmacol and Ther 2002;27:44-9.

19. Natalin $R$, Reis $L 0$, Alpendre $C$, et al. Triple therapy in refractory detrusor overactivity: $A$ preliminary study. World J Urol 2010;28:79-85. http://dx.doi.org/10.1007/s00345-009-0400-6

20. Gormley EA, Lightner DJ, Burgio KL, et al. Diagnosis and treatment of overactive bladder (non-neurogenic) in adults: AUA/SUFU Guideline. J Urol 2012;188:2455-63. http://dx.doi.org/10.1016/i. juro.2012.09.079

21. Amend B, Hennenlotter J, Schäfer T, et al. Effective treatment of neurogenic detrusor dysfunction by combined high-dosed antimuscarinics without increased side-effects. Eur Urol 2008;53:1021-8. http:// dx.doi.org/10.1016/i.eururo.2008.01.007

22. Yi J, Jeong SJ, Chung MS, et al. Efficacy and tolerability of combined medication of two different antimuscarinics for treatment of adults with idiopathic overactive bladder in whom a single agent antimuscarinic therapy failed. Can Urol Assoc J 2013;7:E88-E92. http://dx.doi.org/10.5489/cuai.269. Epub 2011 November 2.

23. Buser $\mathrm{N}$, Ivic $\mathrm{S}$, Kessler TM, et al. Efficacy and adverse events of antimuscarinics for treating overactive bladder: Network meta-analyses. Eur Urol 2012;62:1040-60. http://dx.doi.org/10.1016/i. eururo.2012.08.060

Correspondence: Dr. Stéphane Bolduc, Pediatric Urologist, Assistant Professor, Clinician-Scientist, Division of Urology, Centre Hospitalier Universitaire de Québec (CHUQ, CHUL), 2705, Boul. Laurier, R-1742, Québec, Québec, Canada, GIV 4G2; fax : 418-654-2137; sbolduc_2002@yahoo.ca 